\title{
Pharmaceutical Applications of Aloe vera
}

\author{
Huay Chin Heng, Mohd Hanif Zulfakar*, Pei Yuen Ng
}

Faculty of Pharmacy, Universiti Kebangsaan Malaysia, Jalan Raja Muda Abdul Aziz, 50300 Kuala Lumpur, Federal Territory of Kuala Lumpur, Malaysia

Submitted: $10-07-2018$

Revised: 10-08-2018

Accepted: 28-09-2018

${ }^{*}$ Corresponding author Mohd Hanif Zulfakar

Email:

hanifzulfakar@ukm,edu.my

\begin{abstract}
Aloe vera has been used as folk medicine for a host of therapeutic indications of which the inner gel is the component extensively used and studied. Proponents of the use of this plant suggest that it is easily available, economical, and have fewer side effects compared to commercial drug compounds. However, the active constituents and their exact mechanisms have yet to be fully elucidated. This review focuses on the identification of the active constituents and their functional mechanism in the areas of anti-diabetic, anti-inflammatory, wound healing, and antibacterial. Preliminary evidence was found to support the antidiabetic effect which extended to the early stages of the disease with no adverse effects at the dosages used. Although topical application for its anti-inflammatory effect may be delayed and minute, oral administration has shown a significant response. However, too high a dose has been linked with an initial inflammatory reaction. Favorable response to the gel has also been demonstrated to support the use of $A$. vera in wound-healing and as an antibacterial agent, although limited to simple, uncomplicated wounds. Different active constituents such as acemannan and aloin have been suggested for the effects of the plant and this may be interpreted as synergism among different compounds rather than the action of a single compound. Until robust evidence is available, the plant should only be used as an adjunct to other wellestablished evidence-based treatment modalities.
\end{abstract}

Key words: A. vera; Anti-diabetic; Anti-inflammatory; Wound healing; Antibacterial

\section{INTRODUCTION}

Aloe barbadensis Miller, the botanical name of the more commonly known $A$. vera, is one of the approximately 420 species belonging to the family Aloaceae (Boudreau and Beland, 2006; Dagne et al., 2000). Under the same family, the Aloe genus is differentiated from the other six genera by bright yellow-coloured flowers, fleshy leaves, and stamens that are as long as or longer than the perianth (Akinyele and Odiyi, 2007). Of the many species, A. vera, Aloe arborescens, and Aloe ferox are among the more extensively studied species. The use of $A$. vera has sustained the passage of time, which dates back to 1750 B.C. in which there is evidence to suggest that the plant has been used as medicinal treatment in Mesopotamia (Shelton, 1991). Originating from South Africa, they are now found widespread and thrive in the dry climates of subtropics and tropics, including Malaysia (Boudreau and Beland, 2006).

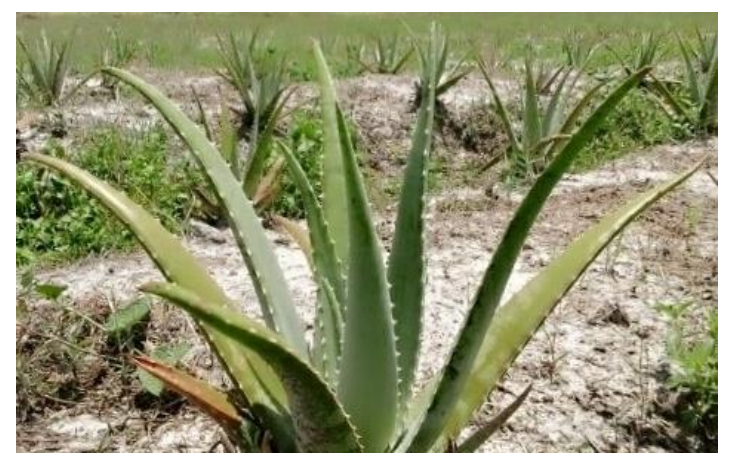

Figure 1. Aloe vera plant.

The triangular fleshy leaves are lined with spines and are arranged in a rosette pattern (Figure 1) (Cole and Heard, 2007; Morton, 1961; Shelton, 1991). Each leaf is being made up of three distinct layers (Figure 2) and as follows: 1 The outermost layer is a thick rind of 15-20 cells in which proteins and polysaccharides such as highly-acetylated glucomannans are produced (Rahman et al., 2017; Shi et al., 2017). 2 The 
middle layer which contains the yellow sap exuded by peripheral bundle sheath cells covers the gel surface and has anthraquinones and glycosides as its constituents. 3 The innermost layer that originates from the clear central mucilaginous pulp is made up mainly of water (Rahman et al., 2017; Shelton, 1991). Initially, the yellow latex of the plant was collected and used as a bitter cathartic, then, an array of other medicinal uses involving the inner clear gel were later discovered (Morton, 1961).

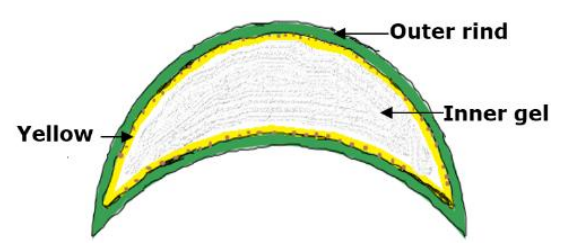

Figure 2. Cross-section of Aloe vera leaf.

The plant has been used for its wound healing, ultraviolet (Veerasubramanian et al. 2018) protective, anti-inflammatory, laxative, antiviral and antitumour, moisturising and antiaging, and antiseptic effects (Surjushe et al, 2008). However, as the use of $A$. vera is further studied, conflicting results pertaining to its effects are discovered. This is further compounded by the lack of understanding of the biochemical components of the plant and their mechanism of action. Scientific research as such has been intensified for a better understanding on these aspects, however; results have been inconsistent, suggesting that perhaps it is not only one active biochemical compound responsible for the effects but a result of the interplay of many active components within the plant. Therefore, this review focuses on establishing the active constituents and their functional mechanism in areas where $A$. vera has been extensively studied (i.e. anti-diabetic, antiinflammatory, wound healing, and antibacterial) (Figure 3, 4, 5 and 6).

\section{ANTI-DIABETIC}

Diabetes mellitus is a non-communicable disease characterized by chronic hyperglycemia and other metabolic derangements. Mainly the body's resistance to insulin, as well as the reduced pancreatic output of the hormone causes it. If not treated, symptoms such as polydipsia, lethargy, polyuria, weight loss, blurred vision, and slow-healing wounds may appear. As the disease continues to deteriorate without being arrested, complications will then develop; this can be divided into macrovascular (cerebrovascular, cardiovascular, peripheral vascular diseases) and microvascular (nephropathy, neuropathy, and retinopathy) complications (Ministry of Health Malaysia, 2015). In Malaysia, the disease has been on an increasing trend, and the most recent prevalence, both reported and unknown, has reached $17.5 \%$ (617, 715 respondents) in those aged 18 years and above as reported by the National Health and Morbidity Survey (NHMS) 2015. Of the above figure, more than a quarter $(25.1 \%)$ of known diabetics claimed that they were on insulin (Institute for Public Health, 2015).

A. vera is among the many plants that have been used as traditional remedies for diabetes mellitus, such as Iranian plant Amygdalus bycioides (Moezi et al., 2018), Cuban plant Allophylus cominia (Semaan et al., 2018), tea plant Camellia sinensis L. (Fan et al., 2018), perennial herbs Anoectocbilus roxburgbii and Anoectocbilus formosanus (Tang et al., 2018), and Cichorium intybus L., a vegetable (Ferrare et al., 2018). However, the scientific community is divided on whether $A$. vera is indeed effective in the treatment of diabetes mellitus as new research findings become available. Some studies were in support of this claim (Cárdenas-Ibarra et al., 2017; Devaraj et al., 2013; Huseini et al., 2012), while others negated this claim and have even demonstrated that $A$. vera may lead to hyperglycemia (Beppu et al., 2006; Okyar, et al., 2001). In an investigation by Okyar and colleagues, they have concluded that the leaf pulp extract exerted hyperglycaemic effect in Type II diabetic rats as opposed to the gel extract which demonstrated hypoglycemic effect (Okyar et al., 2001). It is however, important to note that gel and pulp are essentially the same part of the plant, which is the inner parenchymal tissue (Turner et al., 2004). Based on the preparation method, the leaf pulp extract and the leaf gel extract were both derived from the liquid fraction of the parenchymal tissue. However, the doses used for the two groups were different and are not directly comparable: 
Sterols

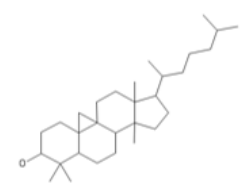

Cycloartanol

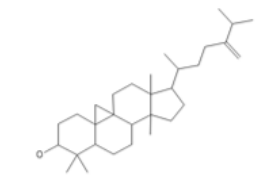

24-methylene-cycloartanol

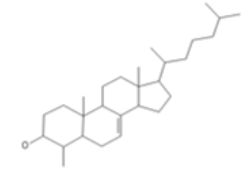

Lophenol

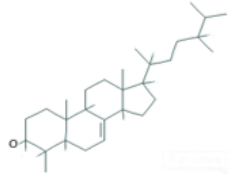

24-methyl-lophenol

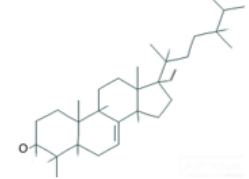

24-ethyl-lophenol

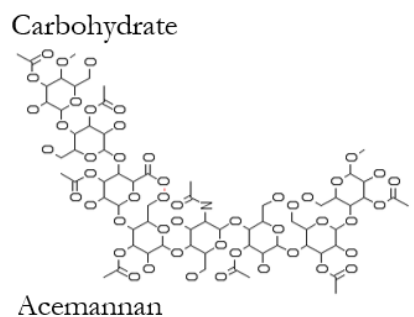

Figure . 3 Some purposed anti-diabetic active compounds of $A$. vera of sterol (Tanaka et al., 2006) and carbohydrate (Huseini et al., 2012)

dose of leaf pulp extract was based on the weight of a lyophilized concentrate while dose of leaf gel extract was based on the volume of a diluted gel. Therefore, the hyperglycaemic effect seen with the gel extract may be simply due to the much lower dose of $A$. vera that may be insignificant in lowering blood glucose. Meanwhile, in another report, administration of A. vera leaf pulp did not significantly alter the blood sugar levels of diabetic mice. This was attributed to the high content of monosaccharides and polysaccharides in the freeze-dried pulp powder that increased the workload of the beta cells of the pancreatic islets (Beppu et al., 2006). Similarly, the dosing regimen used in this study may be flawed: dose was set at a concentration of $2 \%$ of the mice's feed, instead of being determined on the basis of body weight.

On the other hand, the hypoglycaemic effects of the plant were not accompanied by any adverse effects when administered in a randomized, double-blind, placebo-controlled clinical trial. Analysis of blood sugar levels revealed small but significant reductions in fasting blood glucose and glycosylated haemoglobin (HbA1c) levels (Huseini et al., 2012). On the basis of such promising results, efforts have been initiated in developing a concentrate of the active compounds found in the plant. A concentrated form may better demonstrate the efficacy, of which a patented concentrated 5:1 $A$. vera by total process has shown a higher hypoglycemic effect than the corresponding gel (Cárdenas-Ibarra et al., 2017). The observed hypoglycaemic effect may also be beneficial in conditions of prediabetes. Impaired fasting glucose and impaired glucose tolerance could be reverted with administration of a standardized gel preparation, UP780 containing $2 \%$ aloesin as shown in another double-blind, placebo-controlled study. Parameters such as fasting blood glucose, HbA1c, fructosamine, and homeostasis model assessment (HOMA), a marker for insulin resistance were significantly improved with treatment. This finding may support the use of $A$. vera as an addition to therapeutic lifestyle changes in the early stages of the disease, in which initiation of treatment is not yet indicated (Ministry of Health Malaysia, 2015).

Up till today, there has been a race to elucidate the active compounds involved and the mechanisms of the glucose-lowering effect. Five minor phytosterols of the lophenol and cycloartrane structural groups and a glycoside have been postulated to be the active compounds. These fractions of the plant did not result in acute hypoglycaemic conditions and other adverse side effect symptoms (M Tanaka et al., 2006). Meanwhile, the various inorganic elements contained in the leaf gel prepared by ashing the gel may also possess hypoglycaemic activity. Among the many 
elements found in the gel ash, iron, manganese, and potassium were found at higher concentrations (Rajasekaran et al., 2005). Additionally, acemannan, a mucopolysaccharide has been identified as the responsible bioactive (Huseini et al., 2012).

It seems that $A$. vera addresses both the causes of diabetes: insulin resistance and reduced pancreatic output of the hormone. The effect on insulin resistance was supported by the lower levels of glucose and insulin found circulating in blood as a result of increased insulin sensitivity (Manco et al., 2004). On the other hand, preservation of insulin secretion was reflected by the bigger size and the higher number of pancreatic islets seen following administration of $A$. vera gel (Tanaka et al., 2006). Other mechanisms include insulinogenic activity which resulted in higher plasma insulin levels in treated rats (Rajasekaran et al., 2005) and the inhibition of pro-inflammatory state as reflected by lower levels of C-reactive protein (CárdenasIbarra et al., 2017). It has been previously suggested that type II diabetes is associated with higher concentrations of inflammatory mediators that suppress insulin signal transduction. A proinflammatory state therefore can reduce insulin action (Dandona et al., 2004). Meanwhile, others have attributed the production of a fiber-like effect by the high molecular weight polysaccharides present in the gel. As absorption of glucose is slowed down by these polysaccharides, this prevents any blood glucose spikes as manifested by the lower blood glucose levels (Pérez et al., 2007).

\section{ANTI-INFLAMMATORY}

Inflammation can be defined as a pathological process that is a direct consequence from tissue injury, in which the metabolic balance is disrupted and catabolism predominates. The enhanced catabolic state can manifest as: 1) proteolysis, 2) reduction of cellular space volume, and 3) diminished oxidative metabolism over the course of the inflammation process (Stankov, 2012). The causes of inflammation are many and varied; some of the common ones include infection, external injuries, effects of chemicals or radiation, or diseases such as dermatitis. If the inflammation is severe enough, some general reactions happen in the body. The accompanying signs and symptoms include a general feeling of sickness, malaise, fever, and an increase in the number of immune defence cells (PubMed Health, 2015).

Interestingly, certain plants may have anti-inflammatory activity as demonstrated by studies on these plants. Apart from A. vera, these include traditional Brazilian medicine Cissus sicyoides L. (Salazar et al., 2018), camphor tree Cinnamomum camphora (Li et al., 2018), Cordia dichotoma (Hatware et al., 2018), Garcinia morella fruit (Choudhury et al., 2018), and Syzygium calophyllifolium bark (Chandran et al., 2018). The anti-inflammatory effect of $A$. vera has been found comparable to two groups of compounds with established anti-inflammatory activity: NSAIDs such as indomethacin (Devaraj and Karpagam, 2011), piroxicam (et al., 2011), and diclofenac (Egesie et al., 2011), and steroids such as dexamethasone (Vázquez et al., 1996) and hydrocortisone (Hutter et al., 1996). As an inflammatory disease model, ulcerative colitis has shown a favourable response to the gel in which the histological disease activity was decreased in mild to moderate disease (Langmead et al., 2004; Park et al., 2011). However, topical administration of the gel showed a delayed anti-inflammatory effect for 48h. Although significance in the antiinflammatory action was demonstrated afterwards, the action was similar to a hydrophilic placebo gel used as a negative control in the study even when used at a high concentration of $97.5 \%$ (Reuter et al., 2008). Despite the favourable response seen with oral administration, it should be used with caution at high dose as an initial flare in inflammation has been observed. This was seen for the first $0.5 \mathrm{~h}$ when $50 \mathrm{~g}$ wet gel $/ \mathrm{kg}$ body weight was used as compared to $25 \mathrm{~g}$ wet gel $/ \mathrm{kg}$ body weight that lacked such initial proinflammatory phase. The initial flare may be attributed to the higher cytotoxicity at higher dose as compared to the lower dose (Paul et al., 2014). The gel may have been extensively studied for its anti-inflammatory properties but even the flowers of the plant may also have such properties. A $70 \%$ ethanolic extract of the flowers has been shown to be rich in vanillic acid, postulated to be the active constituent. 


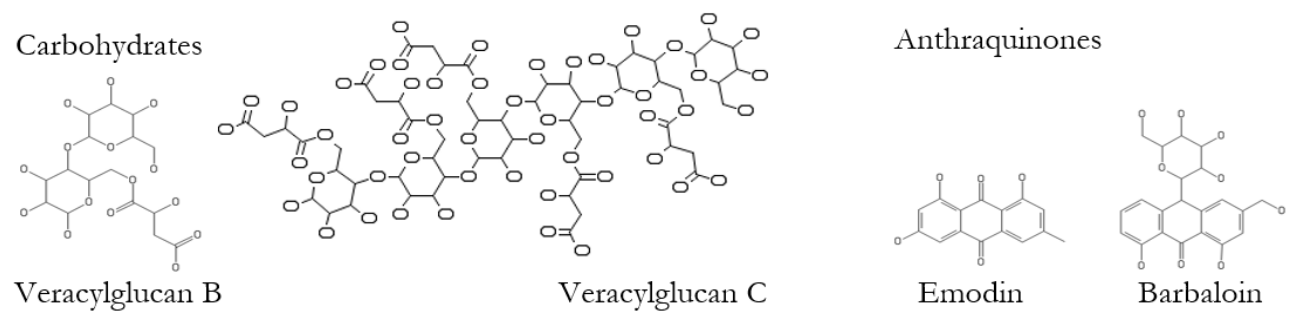

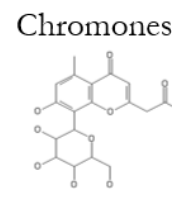

Aloesin

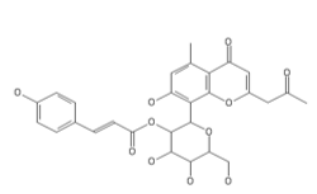

aleresin $\mathrm{A}$

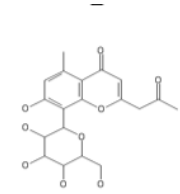

aleresin B

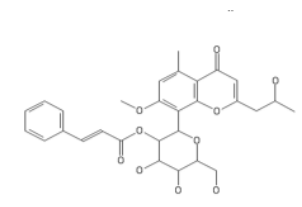

C-glucosylchromone
Others

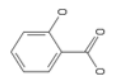

Salicylic acid

Figure 4. Some purposed anti-inflamatory active compounds of $A$. vera of Carbohydrates (Esua and Rauwald, 2006), Anthraquinones (Park et al., 2011; Robson et al., 1982) and Chromones (Hutter et al., 1996; Park et al., 2011; Yagi et al., 2002) and others (MC Robson et al., 1982))

The effect is achieved by scavenging activities on 2,2-diphenyl-1-picrylhydrazyl (DPPH), 2,2'azinobis-3-ethylbenzothiazoline-6-sulfonic acid (ABTS), superoxide, and hydroxyl radicals (Debnath et al., 2017).

Sterols present in the gel have been suggested as the principal component responsible for the anti-inflammatory properties as their structure is similar to the antiinflammatory steroids (Vázquez et al., 1996). Salicylic acid is also one of the organic constituents of the plant apart from barbaloin and emodin which are precursors to aspirin-like compounds (Figure 4). These, in turn, can be broken down by the Kolbe reaction to result in salicylates which possess anti-inflammatory action (Robson et al., 1982). Also known as barbaloin, aloin is mainly found in plant exudate and has previously been used for its cathartic effect (PubChem). To suppress inflammatory responses without the presence of side effect, the safe intake level of aloin has been determined to be at $0.005-0.01 \%$ of diet. Although when compared to aloesin which is an aloe chromone, it was found that the anti-inflammatory effect strength the later was stronger (Park et al., 2011). Its derivatives, aleresin A ( $\mathrm{p}$-coumaroylaloesin) and aleresin B (feruloylaloesin) have also demonstrated anti-inflammatory effect (Yagi et al., 2002). Meanwhile, others have suggested protein (Das et al., 2011; Yagi et al., 1982), glycoprotein (Yagi et al., 1982; Yagi et al., 2003), 540 Da C-glucosylchromone (Hutter et al., 1996), and 20-100 kDa bradykininase (BautistaPérez et al., 2004) as the active constituent. In another research work, veracylglucan $\mathrm{B}$ and veracylglucan $C$ which are malic acid acylated carbohydrates have also been shown to possess anti-inflammatory properties (Esua and Rauwald, 2006).

The anti-inflammatory action of $A$. vera may lie in the reduction of pro-inflammatory mediators: leukotriene B4 (LTB4) (Park et al., 2011) and nitric oxide (NO) (Park et al., 2009), and cytokines: tumor necrosis factor- $\alpha$ (TNF- $\alpha$ ) and interleukin-1ß (IL-1 $\beta$ ) (Habeeb et al., 2007; Park et al., 2011). The inhibitory effect may be seen at the molecular level whereby there was reduced TNF- $\alpha$ and IL-1 $\beta$ MRNA expression (Habeeb et al., 2007; Park et al., 2011). It may also result from an inhibitory effect on the inflammatory mediators of which an antibradykinin activity has been observed (Ro Bautista-Pérez et al., 2004; Yagi et al., 1982). This is complemented by inhibitory effect on important enzymes involved in the inflammatory cascade such as lipoxygenase (LOX) and cyclooxygenase (COX) (Das et al., 2011; Vázquez et al., 1996; Yagi et al., 2003). A reduction in the levels of thromboxane A2 
synthase (Yagi et al., 2003) and hence its metabolite product, thromboxane B2 (Robson $e t$ al., 1982), and matrix metalloproteinase-9 (MMP-9) (D Vijayalakshmi et al., 2012) might further contribute to the effect. Such inhibition also occurred at the molecular level whereby the inhibition of COX-2 MRNA led to reduced levels of prostaglandin E2 (Park et al., 2011). Similarly, inhibition of the expression and production of inducible nitric oxide synthase (iNOS) MRNA (Park et al., 2009) and the expression of MMP-9 mRNA has also been demonstrated (Vijayalakshmi et al., 2012).

\section{WOUND HEALING}

The process of wound healing is initiated as soon as the normal anatomical structure and function of the skin is compromised. The continuous process may be divided into four different stages, each with their own mechanism: 1) coagulation and hemostasis partaken by endothelial cells and thrombocytes, 2) acute inflammation involving the activation of complement cascade and neutrophil infiltration into the wound site, 3) proliferation characterized by migration of fibroblasts and the deposition of a new extracellular matrix, and lastly, 4) wound remodeling with scar tissue formation (Velnar et al., 2009). A variety of plants have been used since medieval time to heal wounds. In the aloe genus, $A$. vera has shown higher wound healing activity than that achieved using other aloe species: Aloe ferox and Aloe marlotbii (Fox et al., 2017). Apart from $A$. vera, other plants believed to possess woundhealing capability include the leaves of Lafoensia pacari A. St.-Hil, a native Brazilian tree (Pereira et al., 2018), Sanguisorba officinalis L. (Zhang et al., 2018), oat Avena sativa (Veerasubramanian et al., 2018), Artemisia khorassanica (Nowrozani and Ranjbary, 2018), and Roman chamomile Chamaemelum nobile L. (Kazemian et al., 2016).

Promising results with $A$. vera have been observed in different wound models. In burn wound model, second-degree burns which involve damage to the epidermis and dermis (Akhoondinasab et al., 2014; Hosseinimehr et al., 2010; Khorasani et al., 2009), and even thirddegree burns which extend beyond the dermis into the deeper tissues (Akhoondinasab et al., 2014; Rodriguez-Bigas et al., 1988) have shown favorable responses. Such effects have also been demonstrated in full-thickness excisional wound model (Khan et al., 2013; Li et al., 2017; Wahedi et al., 2017), full-thickness incisional wound model (Mendonça et al., 2009; Tarameshloo et al., 2012), superficial wound model involving postdermabrasion wounds (Fulton, 1990), and internal wound model involving induced gastric ulcers (Eamlamnam et al., 2006). The potential of $A$. vera in wounds characterised by delayed healing such as in acute-radiation delayed wounds and diabetic wounds has also been demonstrated (Atiba et al., 2011; Atiba et al., 2011). Although most of the favourable responses were demonstrated in animal model, the effect has been supported by a prospective, randomized, double-blind, placebo-controlled trial involving post-operative patients (Eshghi $e t$ al., 2010). On the contrary, administration of the gel in addition to standard wound care has shown delayed healing of vertical incisions as compared to the group receiving standard wound care. This may indicate that the gel treatment is not suitable for those who had wound complications requiring healing by second intention (Schmidt and Greenspoon, 1991). It is also interesting to note that a more frequent administration may lead to higher healing capacity as demonstrated by twice daily topical administration of the gel as compared to once daily application (Takzare et al., 2009).

One of the active components identified as having cell-proliferation activity was a $5.5 \mathrm{kDa}$ glycoprotein fraction (Choi et al., 2001), although this may be antagonized by Veracylglucan C which have shown anti-proliferative effects (Esua and Rauwald, 2006). In another study, a high molecular weight polypeptide has been suggested as the responsible constituent (Heggers et al., 1996). Aloesin (Wahedi et al., 2017) and aloin (Li et al., 2017) which are among the main constituents of $A$. vera exudate may also have a role to play in hastening wound healing.

The underlying mechanisms of the enhanced wound-healing process are likely to start from the second phase of the woundhealing process (inflammation) (Guo and DiPietro, 2010). At this stage, higher levels of neutrophils and macrophages were seen in the treated group (Takzare et al., 2009; Wahedi et al., 2017) which then decreased on Day 7 (Wahedi et al., 2017). The higher number of neutrophils 


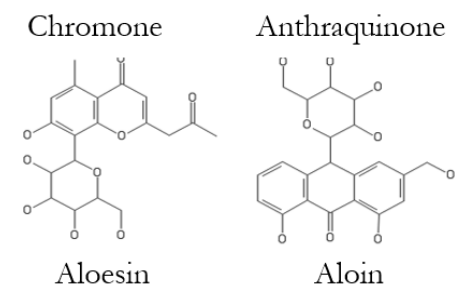

Figure 5. Some purposed wound healing active compounds of $A$. vera of chromones (Wahedi et al., 2017) and antraquinone (Li et al., 2017).

enhanced the removal of microbes and cellular debris in the wound but at the same time, neutrophils also produce chemical substances that may cause some damage such as reactive oxygen species and proteases. Meanwhile, macrophages function to promote the inflammatory response by releasing cytokines and also inducing and clearing apoptotic cells including neutrophils as the wound enters the proliferative phase (Guo and DiPietro, 2010).

Subsequently, the proliferative phase was found to be enhanced yet still occurring in a controlled manner. The enhanced cell proliferation resulted from a shortening of the Gap 0 (resting phase) / Gap 1 (interphase) of the cell cycle, and thus an extension of the $\mathrm{S}$ phase (DNA synthesis) (Li et al., 2017). The enhanced proliferation was also contributed by the faster migration of fibroblasts mediated through phosphorylation of $\mathrm{Cdc} 42$ and Rac1, and upregulation of $\alpha$-P-21 activated kinase $(\alpha-\mathrm{PAK})$ which are migration-related proteins ( $\mathrm{Li}$ et al., 2017; Negahdari et al., 2017; Wahedi et al., 2017). With a high number of fibroblasts, higher levels of extracellular matrix (ECM) components such as glycosaminoglycan (GAG), hyaluronic acid, proteoglycan, and dermatan sulfate could be synthesised (Chithra et al., 1998). Higher amounts of collagen, another component of the extracellular matrix were also produced and the newly-formed collagen fibres showed superior alignment compared to untreated wounds which may prevent the formation of a scar tissue ( $\mathrm{Li}$ et al., 2017; Oryan et al., 2010; Wahedi et al., 2017). On the contrary, in another research work, such a proliferative effect on fibroblasts was not observed but the fibroblasts were more matured and better aligned (Oryan et al., 2010). The levels of glycohydrolases in wound granulation tissue were also found to be elevated in $A$. vera treated groups. The few glycohydrolases studied include beta-glucuronidase, N-acetyl glucosaminidase, beta-glucosidase, and beta-galactosidase which are implicated in the turnover of the extracellular matrix (Chithra et al., 1998). Furthermore, Smad (an abbreviation from the fusion of Caenorhabditis elegans Sma genes and the Drosophila Mad, Mothers against decapentaplegic) and mitogen activated protein kinase (MAPK) signaling proteins which are key players in cell migration, angiogenesis, and tissue development were also activated (Wahedi et al., 2017). Angiogenesis, the generation of new capillaries from existing vasculature in granulation tissue was found enhanced with $A$. vera treatment, consistent with the upregulation of angiogenic growth factors (Li et al., 2017; Ucuzian et al., 2010; Wahedi et al., 2017). The higher expression of the following growth factors might also have a role: vascular endothelial growth factor (VEGF) (Atiba et al., 2011; Oryan et al., 2010; Tarameshloo et al., 2012), transforming growth factor -1 (TGF- $\beta$-1) (Atiba et al., 2011; Hormozi et al., 2017; Wahedi et al., 2017), and basic fibroblast growth factor (bFGF) (Atiba et al., 2011; Hormozi et al., 2017). The effect of $A$. vera on the expression of TGF- $\beta-1$ and bFGF in particular, was found to be dose- and timedependent in which the expression decreased significantly after $24 \mathrm{~h}$. This seems like a feedback mechanism to prevent the overproduction of these growth factors as it may lead to an accumulation of matrix proteins and hence, the formation of a hypertrophic scar (Hormozi et al., 2017). In the final phase of the wound-healing process, the collagen fibres were characterised by a higher degree of cross-linking, resulting in enhanced wound strength (Chithra et al., 1998). 
As such, researchers have attempted to incorporate $A$. vera into formulations in order to develop functional wound dressings. In particular, electrospinning has been used to produce nanofibrous dressings with polylacticco-glycolic acid (PLGA) (Garcia-Orue et al., 2017) or polyvinyl alcohol (Sirima et al., 2017) as the polymeric matrix. Loading of recombinant human Epidermal Growth Factor (rhEGF) into these dressings was then carried out, which together with $A$. vera, enhanced fibroblast proliferation, demonstrating the synergistic effect of these two compounds was not affected by the electrospinning process. Incorporation of A. vera extract also increased the viscosity and conductivity of the polymeric solution, which facilitated the electrospinning process (Sirima $e t$ al., 2017). In addition, it provided greater elasticity and tensile strength to the membranes (Garcia-Orue et al., 2017). Incorporation into different types of matrices resulted in different release rate of $A$. vera owing to the different mechanisms involved. In electrospun films, an inverse trend between the content of $A$. vera and the release rate was observed. This was attributed to the increasing fibre diameter with increasing $A$. vera content and hence, a reduction in the surface area of the films. On the contrary, a higher content in hydrogel films led to higher release rates. As $A$. vera content increased, pore expansion was enhanced which facilitated water entry into the hydrogel films (Sirima et al., 2017). Meanwhile in another research work, chitosanalginate (CA) and chitosan-xanthan (CX) membranes loaded with aloin have also been developed as wound dressings. CA membranes have the characteristics of being more stable in liquid media and showed higher values of elongation at break while CX membranes showed sustained release of aloin up to $5 \mathrm{~h}$ which resulted from the cross-linking process with calcium ions (Bierhalz et al., 2017).

\section{ANTIBACTERIAL}

Bacteria are microscopic unicellular organisms characterized by the lack of a membrane-bound nucleus and other organelles, therefore ranked together with prokaryotes, which are single-celled organisms ( $\mathrm{K}$ Rogers, 2010). Bacteria are then further categorized into Gram-positive and Gram-negative based on the results of Gram stain, a classification system based on morphology. Gram-negative microorganisms possess an outer lipid-rich membrane above the peptidoglycan layer as opposed to the single peptidoglycan layer in Gram-positive microbes, which allows the use of Gram stain to distinguish between them (Amyes, 2013; Beveridge, 1999). The emergence of multidrug resistant bacteria has rendered some antibiotics ineffective and the antibacterial activity of naturally-occurring antimicrobials can potentially contribute to the discovery of novel antibiotics. The antibacterial effect of a number of plants has been demonstrated; these include hardy kiwifruit leaves, Actinidia arguta (Almeida $e t$ al., 2018), vine shoot extracts of Tinta Roriz variety (Moreira et al., 2018), garden sage Salvia officinalis L (Wei et al., 2018), Beach spider lily Hymenocallis littoralis (Nadaf et al., 2018), and even the common garlic Allium satioum. I. (Cavallito and Bailey, 1944).

A. vera has also exhibited a broad range of antibacterial activity, although with varying susceptibility (Robson et al., 1982). Bacilli, were particularly susceptible to the antibacterial effect, which has been demonstrated in Bacillus cereus (Pellizzoni et al., 2012), Bacillus subtilis (G Yebpella et al., 2011), Bacillus megaterium (Subramanian et al., 2006), Bacillus sphericus, and Mycobacterium smegmatis. Other susceptible Grampositive microbes include, Enterococcus faecalis, Micrococcus luteus (Alemdar and Agaoglu, 2009), Stapbylococcus aureus (Salah et al., 2017), Methicillin-resistant $S$. aureus (MRSA) (Banu et al., 2012), Staphylcoccus epidermidis (Garcia-Orue et al., 2017), and Streptococcus pyogenes (NejatzadehBarandozi, 2013). Meanwhile, Gram-negative microbes that are susceptible include: Escherichia coli (Salah et al., 2017), Salmonella typhi (Lawrence et al., 2009), Salmonella parathypi (Lorenzetti et al., 1964), Shigella flexneri (Ferro et al., 2003), Alcaligenes faecalis, Aeromonas bydrophilia, Citrobacter fruendii, Serratia marescens, Enterobacter aerogenes (Cock, 2008), Klebsiella pneumoniae, Proteus mirabilis (Dahiya and Purkayastha, 2012), Proteus vulgaris, Agrobacterium tumefaciens (Subramanian et al., 2006), Pseudomonas fluorescens (Cock, 2008), Pseudomonas aeruginosa (Salah et al., 2017), and Vibrio cholera (Mehrotra and rivastava, 2010). Although the antibacterial properties were demonstrated mostly in in-vitro studies, topical application of $A$. vera dressing on patients with non-healing, infected leg ulcers has also shown 


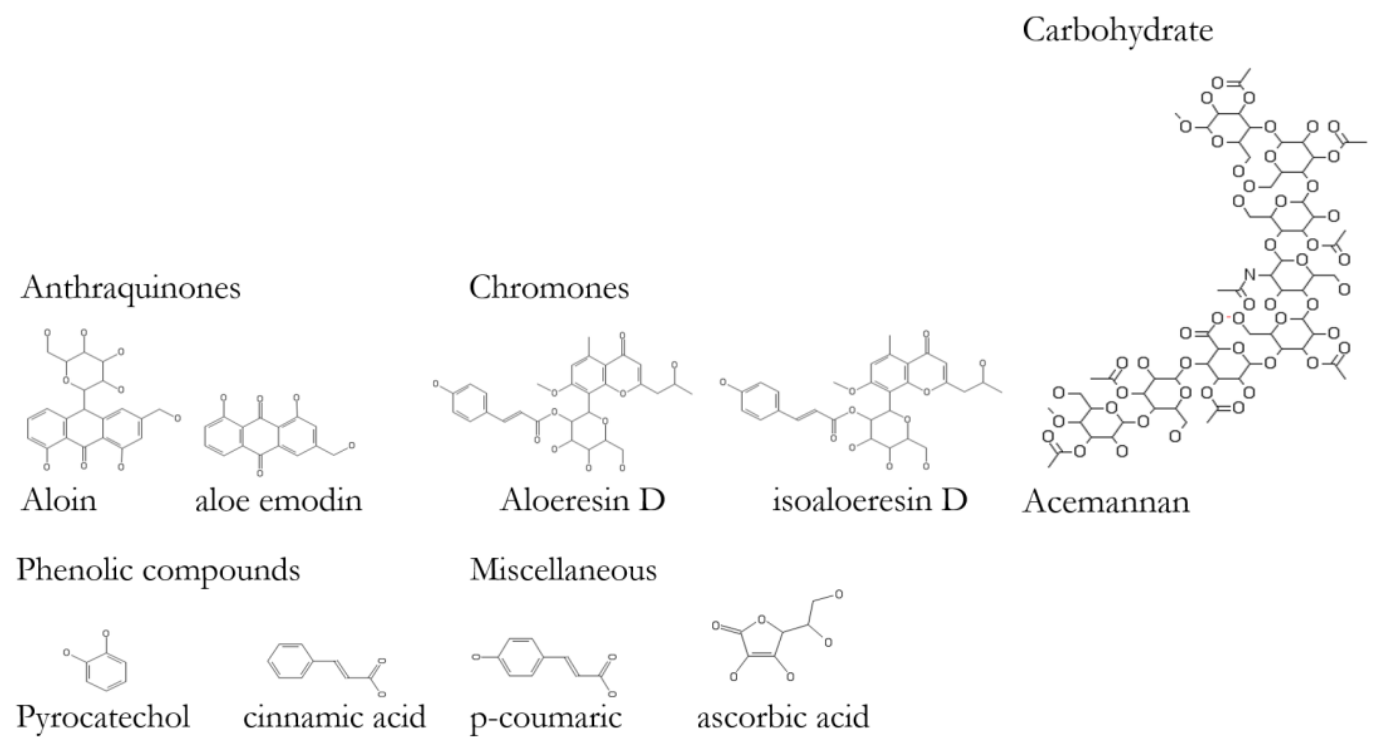

Figure 6. Some purposed antibacterial active compounds of $A$. vera on the Anthraquinones (Pellizzoni et al., 2012), Chromones (Cock, 2008), Carbohydrate (Salah et al., 2017) and Miscellaneous (Lawrence et al., 2009)

favorable responses except in cases of poorly controlled blood glucose (Banu et al., 2012). Albeit the antibacterial effect by $A$. vera was confirmed, Gram-negative microorganisms were less susceptible, which can be attributed to structural differences (Lawrence et al., 2009; Pellizzoni et al., 2012).

The $A$. vera extracts in which different solvents were used (acetone, ethanolic, hexane, chloroform, methanolic, and aqueous) have varying potency of antibacterial effects (Dahiya and Purkayastha, 2012; Irshad et al., 2011; Stanley et al., 2014). The aqueous extract, in particular, showed little or no antimicrobial activity (Dahiya and Purkayastha, 2012). As water is a polar solvent, the aqueous extract may only extract polar active constituents while the use of semi-polar solvents such as alcohols and ketones may induce a certain degree of polarity in non-polar compounds. Therefore, polar and a fraction of non-polar compounds may be found in these semi-polar solvents as opposed to the presence of only polar compounds in water (Abarca-Vargas et al., 2016).

The antibacterial action of $A$. vera may result from the synergism of the many active constituents present. Anthraquinones, aloin (Pellizzoni et al., 2012) and aloe-emodin, and chromones, aloeresin D and isoaloeresin D
(Cock, 2008) are among the active constituents responsible for the antimicrobial effect. Acemannan, a major polysaccharide found in $A$. vera gel has also demonstrated such an effect (Salah et al., 2017). Meanwhile, pyrocatechol and cinnamic acid which are phenolic compounds, $p$ coumaric acid, and ascorbic acid have been suggested as active antibacterial compounds (Lawrence et al., 2009). A phytochemical screen also identified saponins, glycosides, alkaloids, and flavonoids (Yebpella et al., 2011) as the active compounds. The antiMRSA activity may however, be the action of tannins present in the extract (Dahiya and Purkayastha, 2012) (Figure 6).

Exposure to $A$. vera extract reduced the number and size of bacteria apart from shape distortion which may be the result of changes to cell wall structure. The phenolic compound, pyrocatechol is known to denature proteins and disrupt cell membrane (Lawrence et al., 2009). Modification of the physiological properties of the bacterium may also contribute to the antibacterial effect. This involves the diminished ability of the bacterium to consume tryptophan, lactose, and glucose, in addition to the loss of motility and the capability to produce acid and gas (Kargaran et al., 2017; Kouassi and Shelef, 1998). 


\section{CONCLUSION}

There is promising preliminary evidence to support the use of $A$. vera that exhibits impressive functions in the areas of antidiabetic, anti-inflammatory, wound healing, and antibacterial. The antidiabetic effect extends to the early stages of the disease with no presence of side effects at the dosages used. Although topical application for its anti-inflammatory effect may be delayed and minute, oral administration has shown a significant response. However, caution should be practiced as too high a dose has led to an initial inflammatory reaction. Favorable response to the gel has also been demonstrated to justify the use of $A$. vera in wound-healing and as an antibacterial agent, although it should only be used on simple, uncomplicated wounds. A number of different active constituents such as acemannan and aloin have been suggested for its effects and this may be interpreted as an interaction among different compounds rather than the action of a single compound. Currently, there is an increase in the development of processed formulations of $A$. vera to obtain a concentrate of the active compounds; however, the impact of these processing steps should be studied to prevent the degradation of the active compounds and a loss of the desired effect. Further study should be directed in this direction amidst the growing applications of $A$. vera in many aspects.

\section{ACKNOWLEDGEMENT}

The authors would like to thankfully acknowledge the study grant for this review article, which was awarded by the Ministry of Education

(FRGS/1/2016/SKK09/UKM/02/4).

\section{REFERENCES}

Abarca-Vargas R, Peña Malacara CF, Petricevich VL. 2016. Characterization of chemical compounds with antioxidant and cytotoxic activities in bougainvillea $\mathrm{x}$ buttiana holttum and standl,(Var. rose) extracts. Antioxidants. 5(4): 45.

Akhoondinasab MR, Akhoondinasab M, Saberi M. 2014. Comparison of healing effect of aloe vera extract and silver sulfadiazine in burn injuries in experimental rat model. World journal of plastic surgery. 3(1): 29.

Akinyele B, Odiyi A. 2007. Comparative study of the vegetative morphology and the existing taxonomic status of Aloe vera $\mathrm{L}$. Journal of plant Sciences. 2(5): 558-63.

Alemdar S, Agaoglu S. 2009. Investigation of in vitro antimicrobial activity of Aloe vera juice. J Anim Vet Adv. 8(1): 99-102.

Almeida D, Pinto D, Santos J, Vinha AF, Palmeira J, Ferreira HN, ... Oliveira MBP. 2018. Hardy kiwifruit leaves (Actinidia arguta): An extraordinary source of value-added compounds for food industry. Food Chemistry. 259: 11321.

Amyes SG. 2013. Bacteria: a very short introduction: OUP Oxford.

Atiba A, Nishimura M, Kakinuma S, Hiraoka T, Goryo M, Shimada Y, . . Uzuka Y. 2011. Aloe vera oral administration accelerates acute radiation-delayed wound healing by stimulating transforming growth factor- $\beta$ and fibroblast growth factor production. The American Journal of Surgery. 201(6): 809-18.

Atiba A, Ueno H, Uzuka Y. 2011. The effect of aloe vera oral administration on cutaneous wound healing in type 2 diabetic rats. Journal of Veterinary Medical Science. 73(5): 583-89.

Banu A, Sathyanarayana B, Chattannavar G. 2012. Efficacy of fresh Aloe vera gel against multi-drug resistant bacteria in infected leg ulcers. The Australasian medical journal. 5(6): 305.

Bautista-Pérez Ro, Segura-Cobos D, VázquezCruz B. 2004. In vitro antibradykinin activity of Aloe barbadensis gel. Journal of ethnopharmacology. 93(1): 89-92.

Beppu H, Shimpo K, Chihara T, Kaneko T, Tamai I, Yamaji S, ... Sonoda S. 2006. Antidiabetic effects of dietary administration of Aloe arborescens Miller components on multiple lowdose streptozotocin-induced diabetes in mice: investigation on hypoglycemic action and systemic absorption dynamics of aloe components. Journal of ethnopharmacology. 103(3): 468-77.

Beveridge TJ. 1999. Structures of gram-negative cell walls and their derived membrane 
vesicles. Journal of Bacteriology. 181(16): 4725-33.

Bierhalz ACK, Lopes SA, Pires ALR, Moraes ÂM. 2017. Development of polysaccharide-based membranes incorporating the bioactive compound aloin. Int. J Polymeric Materials and Polymeric Biomaterials. 66(4): 193-202.

Boudreau MD, Beland FA. 2006. An evaluation of the biological and toxicological properties of Aloe barbadensis (miller), Aloe vera. J. Environmental Scie Health Part C. 24(1): 103-54.

Cárdenas-Ibarra L, Villarreal-Pérez JZ, LiraCastillo JC, Nava-Alemán A. 2017. Randomized double blind crossover trial of Aloe vera, Cnidoscolus chayamansa and placebo for reducing hyperglycemia in women with early metabolic syndrome. Clinical Nutrition Experimental.

Cavallito CJ, Bailey JH. 1944. Allicin, the antibacterial principle of Allium sativum. I. Isolation, physical properties and antibacterial action. Journal of the American Chemical Society. 66(11): 1950-51.

Chandran R, Abrahamse H, Parimelazhagan T. 2018. Cytotoxic, analgesic and antiinflammatory properties of Syzygium calophyllifolium bark. Biomedicine \& Pharmacotherapy. 103: 1079-85.

Chithra P, Sajithlal G, Chandrakasan G. 1998. Influence of Aloe vera on collagen characteristics in healing dermal wounds in rats. Molecular and Cellular Biochemistry. 181(1): 71-76.

Chithra P, Sajithlal G, Chandrakasan G. 1998. Influence of Aloe vera on the glycosaminoglycans in the matrix of healing dermal wounds in rats. Journal of ethnopharmacology. 59(3): 179-86.

Choi SW, Son BW, Son YS, Park YI, Lee SK, Chung MH. 2001. The wound-healing effect of a glycoprotein fraction isolated from aloe vera. British Journal of Dermatology. 145(4): 535-45.

Choudhury B, Kandimalla R, Elancheran R, Bharali R, Kotoky J. 2018. Garcinia morella fruit, a promising source of antioxidant and anti-inflammatory agents induces breast cancer cell death via triggering apoptotic pathway. Biomedicine \& Pharmacotherapy. 103: 562-73.

Cock IE. 2008. Antimicrobial activity of Aloe barbadensis Miller leaf gel components. The Internet Journal of Microbiology. 4(2): 17.

Cole L, Heard C. 2007. Skin permeation enhancement potential of Aloe Vera and a proposed mechanism of action based upon size exclusion and pull effect. International Journal of Pharmaceutics. 333(1): 10-16.

Dagne E, Bisrat D, Viljoen A, Van Wyk B. 2000. Chemistry of Aloe species. Current Organic Chemistry. 4(10): 1055-78.

Dahiya P, Purkayastha S. 2012. Phytochemical screening and antimicrobial activity of some medicinal plants against multidrug resistant bacteria from clinical isolates. Indian journal of pharmaceutical sciences. 74(5): 443.

Dandona P, Aljada A, Bandyopadhyay A. 2004. Inflammation: the link between insulin resistance, obesity and diabetes. Trends in Immunology. 25(1): 4-7.

Das S, Mishra B, Gill K, Ashraf MS, Singh AK, Sinha M, . . . Singh TP. 2011. Isolation and characterization of novel protein with anti-fungal and anti-inflammatory properties from Aloe vera leaf gel. International Journal of Biological Macromolecules. 48(1): 38-43.

Debnath T, Ghosh M, Lee YM, Nath NCD, Lee K-G, Lim BO. 2017. Identification of phenolic constituents and antioxidant activity of Aloe barbadensis flower extracts. Food and Agricultural Immunology: 1-12.

Devaraj A, Karpagam T. 2011. Evaluation of anti-inflammatory activity and analgesic effect of Aloe vera leaf extract in rats. International Research Journal of Pharmacy. 2(3): 103-10.

Devaraj S, Yimam M, Brownell LA, Jialal I, Singh S, Jia Q. 2013. Effects of Aloe vera supplementation in subjects with prediabetes/metabolic syndrome. Metabolic Syndrome and Related Disorders. 11(1): 35-40.

Eamlamnam K, Patumraj S, Visedopas N, 
Thong-Ngam D. 2006. Effects of Aloe vera and sucralfate on gastric microcirculatory changes, cytokine levels and gastric ulcer healing in rats. World Journal of Gastroenterology. 12(13): 2034.

Egesie U, Chima K, Galam N. 2011. Antiinflammatory and analgesic effects of aqueous extract of Aloe Vera (Aloe barbadensis) in rats. African Journal of Biomedical Research. 14(3): 209-12.

Eshghi F, Hosseinimehr SJ, Rahmani N, Khademloo M, Norozi MS, Hojati O. 2010. Effects of Aloe vera cream on posthemorrhoidectomy pain and wound healing: results of a randomized, blind, placebo-control study. The Journal of Alternative and Complementary Medicine. 16(6): 64750.

Esua MF, Rauwald J-W. 2006. Novel bioactive maloyl glucans from Aloe vera gel: isolation, structure elucidation and in vitro bioassays. Carbohydrate Research. 341(3): 355-64.

Fallah Huseini H, Kianbakht S, Hajiaghaee R, Hashem Dabaghian F. 2012. Antihyperglycemic and antihypercholesterolemic effects of Aloe vera leaf gel in hypercholesterolemic type 2 diabetic patients: a randomized double-blind placebo-controlled clininal trial. Planta Medica. 78: 311-6.

Fan M, Sun X, Qian Y, Xu Y, Wang D, Cao Y. 2018. Effects of metal ions in tea polysaccharides on their in vitro antioxidant activity and hypoglycemic activity. International Journal of Biological Macromolecules.

Ferrare K, Bidel LP, Awwad A, Poucheret P, Cazals G, Lazennec F, . . Tousch D. 2018. Increase in insulin sensitivity by the association of chicoric acid and chlorogenic acid contained in a natural chicoric acid extract (NCRAE) of chicory (Cichorium intybus L.) for an antidiabetic effect. Journal of ethnopharmacology.

Ferro VA, Bradbury F, Cameron P, Shakir E, Rahman SR, Stimson WH. 2003. In vitro susceptibilities of Shigella flexneri and Streptococcus pyogenes to inner gel of Aloe barbadensis Miller. Antimicrobial Agents and Chemotherapy. 47(3): 1137-39.

Fox LT, Mazumder A, Dwivedi A, Gerber M, Du Plessis J, Hamman JH. 2017. In vitro wound healing and cytotoxic activity of the gel and whole-leaf materials from selected aloe species. Journal of ethnopharmacology. 200: 17.

Fulton JE. 1990. The Stimulation of Postdermabrasion Wound Healing with Stabilized Aloe Vera Gel-Polyethylene Oxide Dressing. The Journal of dermatologic surgery and oncology. 16(5): 460-67.

Garcia-Orue I, Gainza G, Gutierrez FB, Aguirre JJ, Evora C, Pedraz JL, ... Igartua M. 2017. Novel nanofibrous dressings containing rhEGF and Aloe vera for wound healing applications. International Journal of Pharmaceutics. 523(2): 556-66.

Guo Sa, DiPietro LA. 2010. Factors affecting wound healing. Journal of Dental Research. 89(3): 219-29.

Habeeb F, Stables G, Bradbury F, Nong S, Cameron P, Plevin R, Ferro VA. 2007. The inner gel component of Aloe vera suppresses bacterial-induced proinflammatory cytokines from human immune cells. Methods. 42(4): 388-93.

Hatware KV, Sharma S, Patil K, Shete M, Karri S, Gupta G. 2018. Evidence for gastroprotective, anti-inflammatory and antioxidant potential of methanolic extract of Cordia dichotoma leaves on indomethacin and stress induced gastric lesions in Wistar rats. Biomedicine \& Pharmacotherapy. 103: 317-25.

Heggers JP, Kucukcelebi A, Listengarten D, Stabenau J, Ko F, Broemeling LD, . . . Winters WD. 1996. Beneficial effect of Aloe on wound healing in an excisional wound model. The Journal of Alternative and Complementary Medicine. 2(2): 271-77.

Hormozi M, Assaei R, Boroujeni MB. 2017. The effect of aloe vera on the expression of wound healing factors (TGF $\beta 1$ and bFGF) in mouse embryonic fibroblast 
cell: In vitro study. Biomedicine \& Pharmacotherapy. 88: 610-16.

Hosseinimehr SJ, Khorasani G, Azadbakht M, Zamani P, Ghasemi M, Ahmadi A. 2010. Effect of aloe cream versus silver sulfadiazine for healing burn wounds in rats. Acta Dermatovenerologica Croatica. 18(1): 0-0.

Huseini HF, Kianbakht S, Hajiaghaee R, Dabaghian FH. 2012. Antihyperglycemic and antihypercholesterolemic effects of Aloe vera leaf gel in hyperlipidemic type 2 diabetic patients: a randomized doubleblind placebo-controlled clinical trial. Planta Medica. 78(04): 311-16.

Hutter JA, Salman M, Stavinoha WB, Satsangi N, Williams RF, Streeper RT, Weintraub ST. 1996. Antiinflammatory C-glucosyl chromone from Aloe barbadensis. Journal of Natural Products. 59(5): 541-43.

Institute for Public Health. 2015. National Health and Morbidity Survey 2015. Institute for Public Health, Malaysia. pp. 315.

Irshad S, Butt M, Younus H. 2011. In-vitro antibacterial activity of Aloe barbadensis Miller (Aloe vera). International research journal of pharmaceuticals. 1(2): 59-64.

Kargaran M, Moradabadi AR, Arjomandzadegan M, Hosseini $H$, Habibi G, Tayeboon M, . . . Akbari A. 2017. Effects of the Aqueous Extract of Aloe vera on the Morphological and Physiological Properties of E. coli. Iranian Red Crescent Medical Journal. 19(2).

Kazemian H, Ghafourian S, Sadeghifard N, Badakhsh B, Heidari H, Taji A, .. . Houri H. 2016. In vivo antibacterial and wound healing activities of Roman chamomile (Chamaemelum nobile). Infectious disorders drug targets.

Khan AW, Kotta S, Ansari SH, Sharma RK, Kumar A, Ali J. 2013. Formulation development, optimization and evaluation of aloe vera gel for wound healing. Pharmacognosy magazine. 9(Suppl 1): S6.

Khorasani G, Hosseinimehr SJ, Azadbakht M,
Zamani A, Mahdavi MR. 2009. Aloe versus silver sulfadiazine creams for second-degree burns: a randomized controlled study. Surgery today. 39(7): 587-91.

Kouassi Y, Shelef LA. 1998. Inhibition of Listeria monocytogenes by cinnamic acid: possible interaction of the acid with cysteinyl residues. Journal of food safety. 18(3): 231-42.

Langmead L, Feakins R, Goldthorpe S, Holt H, Tsironi E, De Silva A, ... Rampton D. 2004. Randomized, double-blind, placebo-controlled trial of oral aloe vera gel for active ulcerative colitis. Alimentary pharmacology \& therapeutics. 19(7): 739-47.

Lawrence R, Tripathi P, Jeyakumar E. 2009. Isolation, purification and evaluation of antibacterial agents from Aloe vera. Brazilian Journal of Microbiology. 40(4): 906-15.

Li L-J, Gao S-Q, Peng L-H, Wang X-R, Zhang Y, Hu Z-J, Gao J-Q. 2017. Evaluation of efficacy of aloin in treating acute trauma in vitro and in vivo. Biomedicine \& Pharmacotherapy. 88: 1211-19.

Li Y-R, Fu C-S, Yang W-J, Wang X-L, Feng D, Wang X-N, . . . Shen T. 2018. Investigation of constituents from Cinnamomum camphora (L.) J. Presl and evaluation of their antiinflammatory properties in lipopolysaccharide-stimulated RAW 264.7 macrophages. J. Ethnopharmacol. 221: 37-47.

Lorenzetti LJ, Salisbury R, Beal JL, Baldwin JN. 1964. Bacteriostatic property of Aloe vera. Journal of Pharmaceutical Sciences. 53: 1287.

Manco M, Calvani M, Mingrone G. 2004. Effects of dietary fatty acids on insulin sensitivity and secretion. Diabetes, Obesity and Metabolism. 6(6): 402-13.

Mehrotra S, Srivastava AK. 2010. Comparative antimicrobial activities of Neem, Amla, Aloe, Assam Tea and Clove extracts against Vibrio cholerae, Staphylococcus aureus and Pseudomonas aeruginosa. Journal of Medicinal Plants Research. 
4(23): 2473-78.

Mendonça FAS, Passarini Junior JR, Esquisatto MAM, Mendonça JS, Franchini CC, Santos GMTd. 2009. Effects of the application of Aloe vera (L.) and microcurrent on the healing of wounds surgically induced in Wistar rats. Acta Cirúrgica Brasileira. 24(2): 150-55.

Ministry of Health Malaysia. 2015. Management of Type 2 Diabetes Mellitus. Malaysia, (Online),

(http://www.moh.gov.my/penerbitan/ CPG/CPG\%20T2DM\%202015.pdf, accessed 1 September 2018).

Moezi L, Arshadi SS, Motazedian T, Seradj SH, Dehghani F. 2018. Anti-Diabetic Effects of Amygdalus Lycioides Spach in Streptozocin-Induced Diabetic Rats. Iranian Journal of Pharmaceutical Research. 17(1): 353-64.

Moreira MM, Barroso MF, Porto JV, Ramalhosa M, Švarc-Gajić J, Estevinho L, . . . Delerue-Matos C. 2018. Potential of Portuguese vine shoot wastes as natural resources of bioactive compounds. Science of The Total Environment. 634: 831-42.

Morton JF. 1961. Folk uses and commercial exploitation of Aloe leaf pulp. Economic Botany. 15(4): 311-19.

Nadaf NH, Parulekar RS, Patil RS, Gade TK, Momin AA, Waghmare SR, . . Sonawane KD. 2018. Biofilm inhibition mechanism from extract of Hymenocallis littoralis leaves. J. Ethnopharmacol. 222: 121-32.

Negahdari S, Galehdari H, Kesmati M, Rezaie A, Shariati G. 2017. Wound healing activity of extracts and formulations of aloe vera, henna, adiantum capillusveneris, and myrrh on mouse dermal fibroblast cells. International journal of preventive medicine. 8 .

Nejatzadeh-Barandozi F. 2013. Antibacterial activities and antioxidant capacity of Aloe vera. Organic and medicinal chemistry letters. 3(1): 5 .

Ni Y, Turner D, Yates K, Tizard I. 2004. Isolation and characterization of structural components of Aloe vera $\mathrm{L}$. leaf pulp. International Immunopharmacology. 4(14): 1745-55.
Nowrozani FR, Ranjbary AG. 2018. Effects of the hydroalcoholic extract of Artemisia khorassanica on wound healing potential in mice. Comparative Clinical Pathology: 1-5.

Okyar A, Can A, Akev N, Baktir G, Sutlupinar N. 2001. Effect of Aloe vera leaves on blood glucose level in type I and type II diabetic rat models. Phytotherapy Research. 15(2): 157-61.

Oryan A, Naeini AT, Nikahval B, Gorjian E. 2010. Effect of aqueous extract of Aloe vera on experimental cutaneous wound healing in rat. Veterinarski arhiv. 80(4): 509-22.

Park M-Y, Kwon H-J, Sung M-K. 2009. Evaluation of aloin and aloe-emodin as anti-inflammatory agents in aloe by using murine macrophages. Bioscience, Biotechnology, and Biochemistry. 73(4): 828-32.

Park M-Y, Kwon H-J, Sung M-K. 2011. Dietary aloin, aloesin, or aloe-gel exerts antiinflammatory activity in a rat colitis model. Life Sciences. 88(11): 486-92.

Paul S, Dutta S, Chaudhuri TK, Bhattacharjee S. 2014. Anti-inflammatory and protective properties of Aloe vera leaf crude gel in carrageenan induced acute inflammatory rat models. Int J Pharm Pharm Sci. 6(9): 368-71.

Pellizzoni M, Ruzickova G, Kalhotka L, Lucini L. 2012. Antimicrobial activity of different Aloe barbadensis Mill. and Aloe arborescens Mill. leaf fractions. Journal of Medicinal Plants Research. 6(10): 1975-81.

Pereira LOM, Vilegas W, Tangerina MMP, Arunachalam K, Balogun SO, OrlandiMattos PE, ... de Oliveira Martins DT. 2018. Lafoensia pacari A. St.-Hil.: wound healing activity and mechanism of action of standardized hydroethanolic leaves extract. Journal of ethnopharmacology. 219: 337-50.

Pérez YY, Jiménez-Ferrer E, Zamilpa A, Hernández-Valencia M, AlarcónAguilar FJ, Tortoriello J, Román-Ramos R. 2007. Effect of a polyphenol-rich extract from Aloe vera gel on experimentally induced insulin resistance in mice. The American 
journal of Chinese medicine. 35(06): 1037-46.

PubChem. Aloin, (Online), (https://pubchem.ncbi.nlm.nih.gov/co mpound/313325\#section=Top, accessed 8 May 2018).

PubMed Health. 2015. What is an inflammation?, (Online), (https://www.ncbi.nlm.nih.gov/pubm edhealth/PMH0072482/, accessed 7 May 2018).

Rahman S, Carter P, Bhattarai N. 2017. Aloe Vera for Tissue Engineering Applications. Journal of functional biomaterials. 8(1): 6 .

Rajasekaran S, Sivagnanam K, Subramanian S. 2005. Antioxidant effect of Aloe vera gel extract in streptozotocin-induced diabetes in rats. Pharmacol Rep. 57(1): 90-6.

Rajasekaran S, Sivagnanam K, Subramanian S. 2005. Mineral contents of Aloe vera leaf gel and their role on streptozotocininduced diabetic rats. Biological Trace Element Research. 108(1-3): 185.

Reuter J, Jocher A, Stump J, Grossjohann B, Franke G, Schempp C. 2008. Investigation of the anti-inflammatory potential of Aloe vera gel $(97.5 \%)$ in the ultraviolet erythema test. Skin pharmacology and physiology. 21(2): 106-10.

Robson MC, Heggers JP, Hagstrom WJ. 1982. Myth, magic, witchcraft, or fact? Aloe vera revisited. The Journal of Burn Care \& Rehabilitation. 3(3): 157-63.

Rodriguez-Bigas M, Cruz NI, Suarez A. 1988. Comparative evaluation of aloe vera in the management of burn wounds in guinea pigs. Plastic and reconstructive surgery. 81(3): 386-89.

Rogers K. 2010. Bacteria and Viruses. Britannica Educational Publishing.

Salah F, El Ghoul Y, Mahdhi A, Majdoub H, Jarroux N, Sakli F. 2017. Effect of the deacetylation degree on the antibacterial and antibiofilm activity of acemannan from Aloe vera. Industrial Crops and Products. 103: 13-18.

Salazar M, Costa JV, Urbina GRO, Cunha VMB, Silva M, do Nascimento Bezerra P, . . . Junior RC. 2018. Chemical composition, antioxidant activity, neuroprotective and anti-inflammatory effects of cipó-pucá (Cissus sicyoides L.) extracts obtained from supercritical extraction. The Journal of Supercritical Fluids. 138: 36-45.

Schmidt JM, Greenspoon JS. 1991. Aloe vera dermal wound gel is associated with a delay in wound healing. Obstetrics \& Gynecology. 78(1): 115-17.

Semaan D, Igoli J, Young L, Gray A, Rowan E, Marrero E. 2018. In vitro anti-diabetic effect of flavonoids and pheophytins from Allophylus cominia Sw. on the glucose uptake assays by HepG2, L6, 3T3-L1 and fat accumulation in 3T3-L1 adipocytes. Journal of ethnopharmacology.

Shelton RM. 1991. Aloe vera. International Journal of Dermatology. 30(10): 679-83.

Shi X-D, Nie S-P, Yin J-Y, Que Z-Q, Zhang LJ, Huang X-J. 2017. Polysaccharide from leaf skin of Aloe barbadensis Miller: Part I. Extraction, fractionation, physicochemical properties and structural characterization. Food Hydrocolloids. 73: 176-83.

Sirima S, Phiriyawirut M, Suttisintong K. 2017. Comparison of the Release of Aloe vera Extracts from Poly (Vinyl Alcohol) Electrospun Fibers and Hydrogel Films for Wound Healing Applications. Paper presented at the Key Engineering Materials.

Stanley MC, Ifeanyi OE, Eziokwu OG. 2014. Antimicrobial effects of Aloe vera on some human pathogens. International Journal of Current Microbiology and Applied Sciences. 3(3): 1022-28.

Subramanian S, Kumar DS, Arulselvan P, Senthilkumar G. 2006. In vitro antibacterial and antifungal activities of ethanolic extract of Aloe vera leaf gel. Journal of plant Sciences. 1(4): 348-55.

Surjushe A, Vasani R, Saple D. 2008. Aloe vera: A short review. Indian journal of dermatology. 53(4): 163.

Takzare N, Hosseini M-j, Hasanzadeh G, Mortazavi H, Takzare A, Habibi P. 2009. Influence of Aloe Vera gel on dermal wound healing process in rat. Toxicology Mechanisms and Methods. 
19(1): 73-77.

Tanaka M, Misawa E, Ito Y, Habara N, Nomaguchi K, Yamada M, . . . Inagaki M. 2006. Identification of five phytosterols from Aloe vera gel as antidiabetic compounds. Biological and Pharmaceutical Bulletin. 29(7): 1418-22.

Tang T, Duan X, Ke Y, Zhang L, Shen Y, Hu B, ... Wu W. 2018. Antidiabetic activities of polysaccharides from Anoectochilus roxburghii and Anoectochilus formosanus in STZ-induced diabetic mice. International Journal of Biological Macromolecules. 112: 882-88.

Tarameshloo M, Norouzian M, Zarein-Dolab S, Dadpay M, Mohsenifar J, Gazor R. 2012. Aloe vera gel and thyroid hormone cream may improve wound healing in Wistar rats. Anatomy \& cell biology. 45(3): 170-77.

Ucuzian AA, Gassman AA, East AT, Greisler HP. 2010. Molecular mediators of angiogenesis. Journal of burn care \& research: official publication of the American Burn Association. 31(1): 158.

V Stankov S. 2012. Definition of inflammation, causes of inflammation and possible anti-inflammatory strategies. The open inflammation journal. 5(1).

Vázquez B, Avila G, Segura D, Escalante B. 1996. Antiinflammatory activity of extracts from Aloe vera gel. Journal of ethnopharmacology. 55(1): 69-75.

Veerasubramanian PK, Thangavel P, Kannan R, Chakraborty S, Ramachandran B, Suguna L, Muthuvijayan V. 2018. An investigation of konjac glucomannankeratin hydrogel scaffold loaded with Avena sativa extracts for diabetic wound healing. Colloids and Surfaces B: Biointerfaces. 165: 92-102.

Velnar T, Bailey T, Smrkolj V. 2009. The wound healing process: an overview of the cellular and molecular mechanisms. Journal of International Medical Research. 37(5): 1528-42.

Vijayalakshmi D, Dhandapani R, Jayaveni S, Jithendra PS, Rose C, Mandal AB. 2012.
In vitro anti inflammatory activity of Aloe vera by down regulation of MMP9 in peripheral blood mononuclear cells. Journal of ethnopharmacology. 141(1): $542-46$.

Wahedi HM, Jeong M, Chae JK, Do SG, Yoon H, Kim SY. 2017. Aloesin from Aloe vera accelerates skin wound healing by modulating MAPK/Rho and Smad signaling pathways in vitro and in vivo. Phytomedicine. 28: 19-26.

Wei Z-F, Zhao R-N, Dong L-J, Zhao X-Y, Su JX, Zhao M, ... Zhang L-J. 2018. Dualcooled solvent-free microwave extraction of Salvia officinalis $\mathrm{L}$. essential oil and evaluation of its antimicrobial activity. Industrial Crops and Products. 120: 71-76.

Yagi A, Harada N, Yamada H, Iwadare S, Nishioka I. 1982. Antibradykinin active material in Aloe saponaria. Journal of Pharmaceutical Sciences. 71(10): 117274.

Yagi A, Kabash A, Mizuno K, Moustafa S, Khalifa T, Tsuji H. 2003. Radical scavenging glycoprotein inhibiting cyclooxygenase- 2 and thromboxane A2 synthase from aloe vera gel. Planta Medica. 69(03): 269-71.

Yagi A, Kabash A, Okamura N, Haraguchi H, Moustafa S, Khalifa T. 2002. Antioxidant, free radical scavenging and anti-inflammatory effects of aloesin derivatives in Aloe vera. Planta Medica. 68(11): 957-60.

Yebpella G, MM AH, Hammuel C, Magomya A, Agbaji A, Okonkwo E. 2011. Phtyochemical screening and comparative study of antimicrobial activity of Aloe vera various extracts. African Journal of Microbiology Research. 5(10): 1182-87.

Zhang H, Chen J, Cen Y. 2018. Burn wound healing potential of a polysaccharide from Sanguisorba officinalis L. in mice. International Journal of Biological Macromolecules. 112: 862-67 